\title{
THE SECULAR INFLATION TERM IN OPEN-ECONOMY PHILLIP, CURVES
}

\author{
Charles ENGEL \\ University of Virginia, Charlottesville, VA 22901, USA \\ Jeffrey FRANKEL \\ Unirsrsity of California, Berkeley, CA 94720, USA
}

Received February 1983, final version received November 1983

Robert Flood has compared three alternative specifications for the secular inflation term in a1 open-economy Phillips curve, attributed, respectively, to Buiter-Miller, and Frankel and Mussa We point out (1) an arithmetic error, (2) the equivalence of the Frankel and Mussa versions, anı (3) some arguments against the Buiter-Miller version.

In a recent paper in this Review, Eluiter and Miller studied the effects o monetary contraction, for example, overshooting of the exchange rate, in : familiar kind of open-economy macroeconomic model that appends : secular inflation term to the Phillips curve. In his comment, which appearer together with the Buiter-Miller paper, Flood examined the consequences 0 three alternative ways of modeling the secular inflation term, using specifi parameter values as an example. The three were (a) the 'Buiter-Miller specification in which the secular inflation term $\pi$ adjusts only gradually ove time toward the actual rate of price change $\dot{p}$, (b) the 'Frankel' specification in which $\pi$ is the same as the money growth rate $\mu$, and (c) the 'Mussa specification, in which $\pi$ is the rate of change of an equilibrium price level $o$ wage rate $\bar{w}$, defined such that if the actual price level or wage rate wer equal to it, there would be no excess demand or supply. All thre specifications give the same answer $(\pi=\dot{p}=\mu=\overline{\bar{w}})$ in long-run equilibrium. but the short-run implications can vary.

We wish to make three brief points, in increasing order of generality.

First, when Flood plugged the parameter values into the exchange rat equation under the Frankel specification, he made an arithmetic error. $\mathrm{Hi}$ equation (6) should be

$$
\epsilon^{\prime}=-1 / 3 w+4 / 3 m+4 / 3\left[2 \mu+2\left(r^{*}-r d\right)-\theta\right],
$$

where $e$ is the exchange rate, $w$ the wage rate. $m$ the money supply, $r^{*}$ th 
foreign interest rate, $r d$ the domestic interest rate, and $\theta$ the level of the value-added tax. With a correction of an additional error in the calculation of $\partial \pi / \partial \mu$ under the Mussa specification, table 1 is altered. Now the Frankel, Buiter-Miller and Flood specifications are all very close. This invalidates Flood's sentence: 'The striking features of this table are the extent to which the results of the Buiter-Miller and Mussa versions match closely and the extent to which they both diverge from the Frankel version.'

Table 1

\begin{tabular}{llll}
\hline & \multicolumn{3}{l}{$\pi$ specification. } \\
\cline { 2 - 4 } Experiment & Buiter-Miller & Frankel & Mussa \\
\hline$\partial e / \partial \mu$ & 2.8624 & 2.67 & 2.75 \\
$\begin{array}{l}\text { Output cost of } \\
\text { one unit reduction } \\
\text { in } \mu,\end{array}$ & & & \\
$\int_{0}^{\infty} y(\tau) d \tau$ & 4.00 & 4.00 & 5.50 \\
$\partial \pi / \partial \mu$ & 0.36 & 1.00 & 0.859 \\
\hline
\end{tabular}

Second, the Frankel and Mussa specifications can be alternative representations of the same assumption, for the case of constant money growth. Let us represent the two supposedly alternative equations for the rate of wage change as

and

$$
\dot{w}=\phi_{1} y+\mu
$$

$$
\dot{w}=\phi_{2} y+\dot{\bar{w}},
$$

where $y$ is the $\log$ of excess demand for domertic goods. We imbed the Phillips curve in the rest of the Buiter-Miller model (of section 4), consisting of a money demand equation, an equation giving excess demand as a function of the real exchange rate, uncovered interest parity, and rational expectations. Eqs. (4a) and (4b) seem very different, and it would appear they imply different dynamics in the model. In fact, it is fairly easy to show that the model is identical under (4a) and (4b) with ${ }^{1}$

$$
\phi_{1}=\phi_{2}\left[1+\alpha \delta \lambda \phi_{2}-\alpha(1-k \delta)\right] /\left[1+\alpha \delta \lambda \phi_{2}\right] \text {. }
$$

\footnotetext{
${ }^{1}$ The proof is available on request. Obsteld and Rogoff $(1984$, p. 2) have recently compared the Mussa specification and what they call the Barro-Grossman rule, which they show includes the Frankel specification as a special case. They show that the two specifications, "though apparently quite dissimilar, yield observationally equivalent exchange rate models. Thus, despite the key role of disequilibrium price dynamics, the choice between the two adjustment mechanisms is not necessarily a critical one'.
} 
Here $x$ is the weight of money wages in the price index, $\delta$ is the price elasticity of output demand, $\lambda$ is the interest semi-elasticity of money demand, and $k$ is the output elasticity of money demand. That is, if $(4 a)$ is assumed to be the wage adjustment equation, the model implies (4b) holds, with the relation between $\phi_{1}$ and $\phi_{2}$ given by the equation above. If (4b) is assumed to hold, then eq. (4a) is implied with the same relation holding between $\phi_{1}$ and $\phi_{2}$. The coefficients reported in the table for the Mussa and the Frankel specifications would be identical. Flood gets different results (aside from the arithmetic error) by forcing $\phi_{1}$ and $\phi_{2}$ to be equal. Speaking very loosely, in these models 'everything is proportional to everything else', so it does not matter whether it is $\dot{w}-\mu$ or $\dot{w}-\dot{\bar{w}}$ that is defined to be proportional to $y$, so long as we allow the constant of proportionality to differ.

One might take the view that eqs. (4a) and (4b) are 'structural', and that the $\phi$ 's are behavioral parameters, and so should be set equal in the comparison of the two specifications. But if in the Frankel specification $\phi_{1}=\frac{1}{2}$, as in Flood's comment, then a Mussa equation is implied, with $\phi_{2}=\frac{2}{3}$. Thus, when Flood compares the Frankel specification with $\phi_{1}=\frac{1}{2}$ to the Mussa specification with $\phi_{2}=\frac{1}{2}$, he is in fact comparing a Mussa specification with $\phi_{2}=\frac{2}{3}$ to a Mussa specification with $\phi_{2}=\frac{1}{2}$.

Finally, we wish to call attention to some points relevant to the choice between the Buiter-Miller specification and the other two. In the other two, a change in the money growth rate has an instantaneous effect on the rate of price change $\dot{p}$ (though not on the price level $p$; these are all sticky-price models). Buiter and Miller introduced their sluggishly-adjusting specification of secular inflation to capture what they consider to be the empirical fact that $\dot{p}$ dces not change discontinuously. But there are two arguments against the Buiter-Miller specification.

First, equations, surh as those of Mussa and Frankel, that preclude jumps in $p$ or $w$ but allow jumps in $\dot{p}$ and $\dot{w}$, have a theoretical fourdation in Taylor overlapping contract models. Contrary to the Buiter-Miller equation, if the price level is an average of all contracts in effect, its rate of change can jump discontinuously because there are always some contracts that are expiring. Second, even if one does specify a differential equation for the seculs $\mathrm{r}$ term, $\pi=\zeta(\dot{p}-\pi), \pi$ may have to jump discontinuously in response to a disturbance anyway, if the new path is to be a stable one (Buiter and Miller, 1982, p. 106). If it is indeed an empirical fact that the inflation rate does not change discontinuously, perhaps it is because the rationallyexpected money growth rate dces not often change with a large discontinuity. Truc regime changes are rare, and even when one occurs the market does not necessarly know or believe it. ${ }^{2}$

\footnotetext{
${ }^{2}$ Engel has shown in a discrete-time model similar to the one discussed here that if policyinduced money growth changes usually contribute little to the variance in the money stock from period to period, and the pu slic does not much believe monetary authorities' announcements of policy changes, a ciange in the money growth rate will lead to a change in the inflation rate equal culy to the speed of adjustment of prices $(\phi)$. When $\phi$ is very low, inflation does not jump much in response to an announced change in the policy-prescribed money growth rate.
} 


\section{References}

Buiter, William and Marcus Miller, 1982, Real exchange rate over-shooting and the output cost of bringing down inflation, European Economic Review 18, May/June, 85-123.

Engel, Charles, 1983, Reliability of policy announcements and the effects of monetary policy, Manuscript (University of Virginia, Charlottesville, VA).

Flood, Robert, 1982, Comments on the Buiter and Miller paper, European Economic Review 18, May/June, 125-127.

Frankel, Jelfrey, 1979, On the mark: A theory of floating exchange rates based on real interest differentials, American Economic Review 69, Sept., 610-623.

Mussa, Michael, 1981, Sticky prices and disequilibrium adjustment in a rational model of the inflationary procss, American Economic Review 71, Dec. 1020-1027.

Obstfeld, Maurice and Kenneth Rogoff, 1984, Exchange rate dynamics with sluggish prices under al ternative price-adjustment rules, International Economic Review, forthcoming.

Taylor, John, 1980, Aggregate dynamics and staggered contracts, Journal of Political Economy 88, Feb., 1-23. 